\title{
Deciphering the performance of satellite-based daily rainfall products over Zambia
}

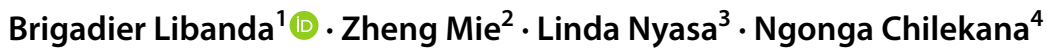

Received: 18 September 2018 / Accepted: 7 April 2020 / Published online: 18 April 2020

(c) The Author(s) 2020

\begin{abstract}
The amount and distribution of precipitation plays a vital role in the management of water resources, agriculture and floodrisk preparedness. Unfortunately, Zambia like many other developing countries is a highly data-scarce country with few and unevenly distributed meteorological stations. The objective of this study was to run a comparative analysis of satellite-based rainfall products (SRPs) and gauge data to ascertain the reliability of using SRPs for daily rainfall measurements in Zambia. The four daily SRPs examined in this study include the following: The Tropical Applications of Meteorology using Satellite and ground-based observations version 3 (TAMSATv3), Precipitation Estimation from Remotely Sensed Information using Artificial Neural Networks (PERSIANN), the Climate Hazards group InfraRed Precipitation with Station data version 2 (CHIRPSv2.0), and the African Rainfall Climatology Version 2 (ARCv2). SRPs were compared to rain gauge data from 35 meteorological, agrometeorological, and climatological stations in Zambia for the period 1998-2015. Statistical analyses were extensively carried out at temporal scales inter alia daily, monthly, seasonal and annual. Comparisons were also done for three stations lying at the highest, middle and lowest elevations to examine the ability of SRPs to capture precipitation occurrences on complex topography. Strong coefficient of determination $(>0.9)$ of all the SRPs and gauge data were found at the monthly scale even over multifaceted topography. However, the ability of these products to capture rain gauge data at daily, seasonal and annual scales differs markedly. Specifically, PERSIANN outperforms all the other SRPs at all scales, CHIRPSv2.0 is rated second, followed by TAMSATv3 and ARCv2, respectively. These results suggest that PERSIANN can reliably be used in studies that seek to estimate rainfall in data-sparse regions of Zambia at any temporal scale and arrive at similar results to rain gauge data.
\end{abstract}

Keywords Precipitation $\cdot$ Satellite-based rainfall products $\cdot$ Gauge data $\cdot$ Zambia

\section{Introduction}

Disentangling the historical variability of precipitation is key to forecasting, water resources management and flood risk preparedness (Maggioni et al. 2013; Tarek et al. 2017). This is especially true in southern Africa where summer floods

Brigadier Libanda

brigadier.libanda@ed.ac.uk

1 School of Geosciences, The University of Edinburgh, Edinburgh EH9 3FF, UK

2 School of Civil Engineering and Geosciences, Newcastle University, Newcastle NE1 4LY, UK

3 Ministry of Lands, Natural Resources and Environmental Protection, P.O. Box 50694, Lusaka, Zambia

4 Ministry of Energy and Water Development, P.O. Box 53930, Lusaka, Zambia are described as 'a way of life'. In fact, rainfall and water related disasters are documented as one of the most damaging environmental risks of the twenty-first century (Miceli et al. 2008). To minimise these losses, accurate measurement of precipitation before input into any hydrological or forecasting system is crucial. Although many meteorological variables require specialist know-how and skill to measure, difficulties with accurate measurements and forecasting are particularly acute with rainfall. This is because precipitation is intrinsically heterogeneous in space and time. Although there is a difference in the scientific definition of rainfall and precipitation (WMO 2010; Met Office 2018), they are used interchangeably in this study.

In many developing countries, access to quality data is a challenge (Awange et al. 2016; Mahmood et al. 2017). This is because meteorological and hydrological stations are usually characterised by low rain gauge distribution to 
area ratios coupled with infrequent observations (Agnihotri et al. 2015; Basheer et al. 2018). This has also augmented hindrances of advances in climate science across many developing nations. Advancing the availability of climate data in developing countries has the potential of facilitating research that will respond to disastrous extreme events, climate-induced health hazards, and ultimately socio-economic development (Washington et al. 2006; Thomson et al. 2011).

While there are different types of rain gauges (see WMO 2010), in Zambia, precipitation is generally measured using World Meteorological Organization (WMO) standard ordinary rain gauges once every $24 \mathrm{~h}$. These rain gauges are point based and record only the amount of rainfall falling over them. This poses a challenge to having a continuous quality-controlled data set because mostly, these gauges are sparsely located and apart from Provincial Meteorological stations (PMSs), most of them are manned by only one observer (One-manned stations). It is important to note that the Zambia Meteorological Department (ZMD) a specialised organ of the government of the Republic of Zambia in charge of weather and climate monitoring only runs ten PMSs. Therefore, most of the remaining stations are manned by only one observer. This highlights the poor staffing levels of ZMD like in many other developing countries. Onemanned stations hinder effective weather and climate monitoring especially in times of ill health. This in turn hampers operational water management and flood forecasting. To overcome this challenge, the use of automatic weather stations to supplement existing manned meteorological stations is being adopted in some countries across Africa (TAHMO 2018). This has future potential to further climate research based on quality observational data sets. In the meantime, scientists employ satellite estimates in many studies around the world. For example, Stampoulis et al. (2013) used satellite data to analyse heavy rainfall events over the Mediterranean, and most recently, Zambrano-Bigiarini et al. (2017) studied the behaviour of satellite rainfall across the complex Chilean topography.

Many research organisations (e.g. The Climatic Research Unit of the University of East Anglia) have developed satellite-based rainfall products (SRPs) to, in part, overcome the challenges of data-scarce regions. The usefulness of SRPs for water management and flood-risk preparedness requires an extensive validation process because generally, SRPs have uncertainties which may cause inaccuracies in flood forecasting and/or model simulations. Many scientists (e.g. Bajracharya et al. 2015; Tarek et al. 2017) have studied SRPs side by side with rain gauge data to understand their ability to capture rain gauge data trends in domains of their interest. These validation studies have also been done, because for effective water resources management and flood forecasting, understanding the precise amount of water entering a catchment or region is crucial as this adds up to antecedent conditions which potentially leads to pluvial and fluvial flooding (Chen et al. 2010; Blanc et al. 2012). Therefore, accurate measurements of rainfall are a key contribution to the advancement of flood forecasting.

While SRPs validation studies have been done in many countries around the world, to our knowledge, none exist for the case of Zambia. To this end, the overall goal of this paper is to evaluate four daily SRPs (i.e. TAMSATv3, PERSIANN, CHIRPSv2.0, and ARCv2) covering the period 1998-2015. Daily SRP data sets were selected, because they provide vital information for decision making processes in flood forecasting (Kar et al. 2015; Tshimanga et al. 2016; Sonkoué et al. 2019) and food security (Stern et al. 1982; Watson and Challinor 2013) that cannot be realised with monthly data sets. This is because most hydrological and agricultural modelling approaches that are used require daily rainfall as an input (Challinor et al. 2004; Clark et al. 2011). These SRPs have been discussed at lengthy in "Data" of this paper. The study period was chosen, because it represents better consistence in station data availability. Results of this study will fill a critical research knowledge gap; particularly, they will strengthen our understanding of the suitability of using SRPs as cost-effective substitutes for daily precipitation measurements in Zambia. Of interest will be the ability of SRPs to mimic rain gauge data across the complex Zambian topography. The findings will also highlight strengths and weaknesses of SRPs (see "Data") which will be useful for developers of these rainfall estimation products.

\section{Study area and climatology}

Zambia is a southern African country bounded by latitudes $8^{\circ}-18^{\circ} \mathrm{S}$ and longitudes $21.8^{\circ}-34^{\circ} \mathrm{E}$. It is land-linked and covers an area of $752,614 \mathrm{~km}^{2}$ (Limao and Venables 2001). Much of the country is on the central African plateau at an average altitude of $1200 \mathrm{~m}$ above mean sea level (Libanda et al. 2018). It has a population of nearly 15 million people (CSO 2010). The inset in Fig. 1 shows the location of Zambia on the map of Africa, while the main figure shows the topographical map of the country. Table 1 presents the longitude, latitude, World Meteorological Organization Station Number and observational frequency of each station.

Zambia experiences a sub-tropical climate. The year-toyear mean accumulative rainfall varies greatly over the country with most areas receiving between 800 and $1200 \mathrm{~mm}$ (Hachigonta et al. 2008). The country receives most of these rains during the summer months of November to March with October and April being months of transition; the rain season is therefore, clearly defined.

Pioneering studies (e.g. Huygen 1989) on synoptic-scale mechanisms and local features affecting the behaviour of rainfall over Zambia suggest that water bodies, e.g. Lake 
Fig. 1 Topographical (m) map of Zambia with red asterisks showing meteorological station density. Inset shows the location of Zambia (green square) on the Map of Africa. Topographical data are based on the 15 arcsecond resolution $(\sim 500 \mathrm{~m})$ SRTM15 Plus which is a fusion of Shuttle Radar Topography Mission (SRTM) land topography with measured and estimated seafloor topography (Becker et al. 2009)
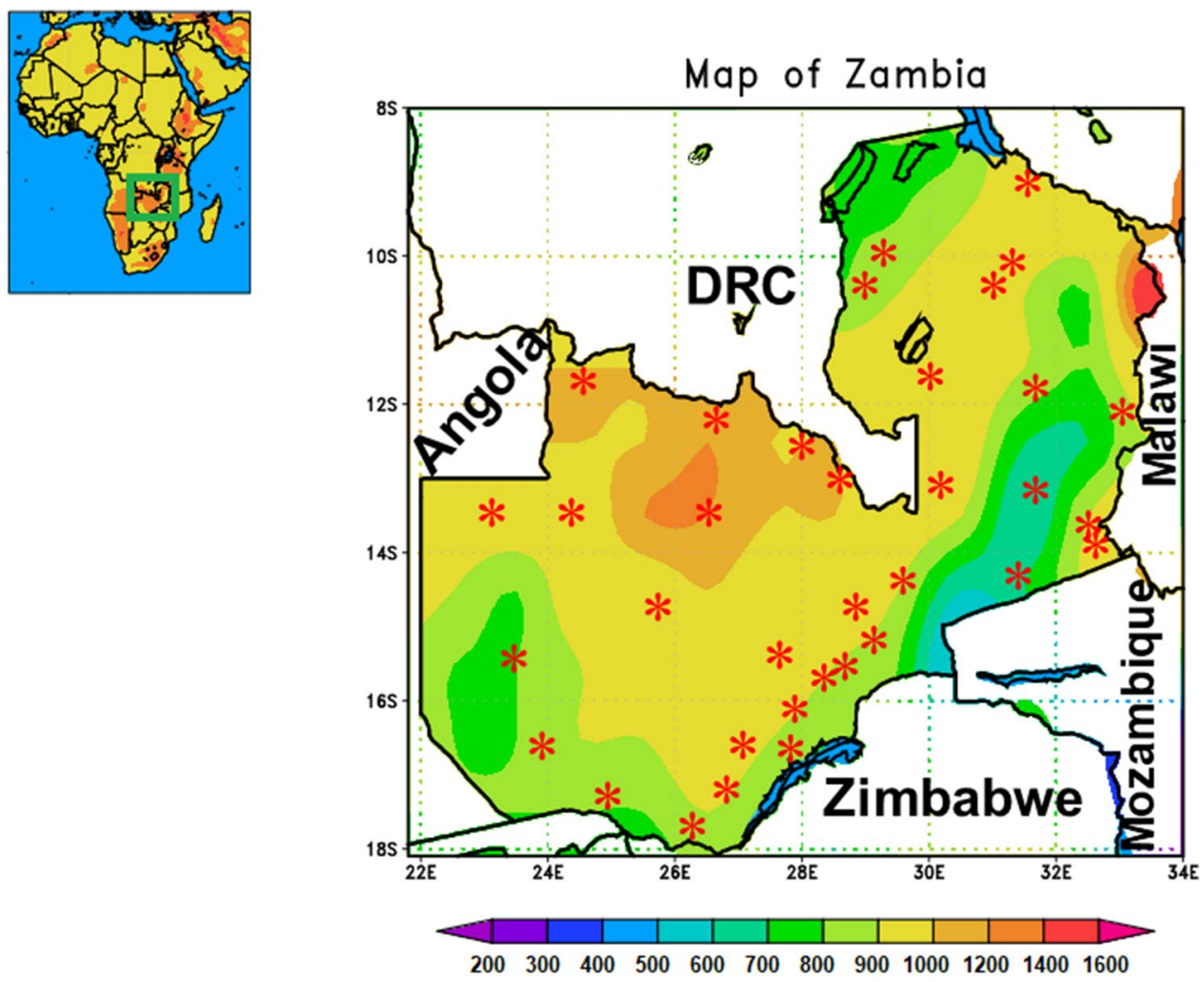

Mweru which covers $5120 \mathrm{~km}^{2}$ in the Northern half of the country, significantly contributes to boosting localised rainfall over some parts of northern Zambia. In similar studies elsewhere, potential evaporation has been documented to be directly correlated to the amount of water available (Majidi et al. 2015). Many studies have also highlighted the causeand-effect relationship of evaporation, cloud formation, and localised precipitation (Lee et al. 2015).

\section{Data}

\section{Gauge data}

The rain gauge data used in this study was kindly provided by the Zambia Meteorological Department (ZMD). ZMD is a specialised organ of the government of the Republic of Zambia in charge of weather and climate monitoring. Even though ZMD was officially recognised as a specialised organ of the Zambian government in January 1967, meteorological and climatological data collection and archiving started in the 1950s under the administration of the Federal Meteorological Services comprising of Nyasaland (Malawi), Northern Rhodesia (Zambia) and Southern Rhodesia (Zimbabwe; Mudenda and Nkonde 2018; ZMD 2020). Daily precipitation data (1998-2015) from 35 meteorological stations (Fig. 1 and Table 1) archived by ZMD was studied sided by side with 4 satellite-based rainfall products (SRPs) to understand the possibility of using SRPs in future research lines to cover data-sparse regions of the country. From "ARCv2" to "PERSIANN", we give an overview of these SRPs.

\section{ARCv2}

Africa Rainfall Climatology Version 2 (ARCv2) was obtained from the archives of the Climate Prediction Centre (CPC) an organ of the National Oceanic and Atmospheric Administration (NOAA); it is freely available here https ://iridl.ldeo.columbia.edu. This data set is a blend of geostationary infrared (IR) data sourced from the European Organisation for the Exploitation of Meteorological Satellites (EUMETSAT) and daily gauge data from the Global Telecommunication System (GTS). ARCv2 is gridded at a spatial resolution of $0.1^{\circ} \times 0.1^{\circ}$, and it is available, in netcdf format, for the period 1983-near present (Novella and Thiaw 2013). It is important to note that as of March 2018, ARCv2 contained 341 days with missing data. This creates a data gap in the evaluation period considered in this study. To facilitate ease comparisons of ARCv2 with other data sets, this gap was filled using Kriging as discussed in the methodologies section.

\section{CHIRPSv2.0}

The Climate Hazards Group InfraRed Precipitation with Station data version 2 data set (CHIRPSv2.0: Funk et al. 
Table 1 Stations used in the study with their longitude, latitude, elevation and WMO numbers

\begin{tabular}{|c|c|c|c|c|c|}
\hline WMO No & Station & Lat $\left[{ }^{\circ} \mathrm{S}\right]$ & Lon $\left[{ }^{\circ} \mathrm{E}\right]$ & Elev $[\mathrm{m}]$ & Obs freq $[\%]$ \\
\hline 67403 & Kawambwa Met & -9.793 & 29.076 & 1334 & 82 \\
\hline 67413 & Mbala Met & -9.028 & 31.553 & 1665 & 100 \\
\hline 67441 & Mwinilunga Met & -11.74 & 24.431 & 1365 & 100 \\
\hline 67461 & Mansa Met & -10.173 & 28.942 & 1257 & 100 \\
\hline 67463 & Samfya Marine-Met & -11.371 & 29.911 & 1194 & 85.27 \\
\hline 67475 & Kasama Met & -10.224 & 31.14 & 1384 & 100 \\
\hline 67476 & Misamfu Agro-Met & -10.171 & 31.225 & 1378 & 90.84 \\
\hline 67477 & Mpika Met & -11.901 & 31.433 & 1399 & 100 \\
\hline 67531 & Zambezi Met & -13.534 & 23.108 & 1065 & 100 \\
\hline 67541 & Kasempa Met & -13.457 & 26 & 1334 & 100 \\
\hline 67543 & Kabompo Met & -13.596 & 24.208 & 1090 & 100 \\
\hline 67551 & Solwezi Met & -12.171 & 26.367 & 1384 & 100 \\
\hline 67561 & Ndola Met & -12.994 & 28.659 & 1269 & 100 \\
\hline 67563 & Kafironda Agro-Met & -12.614 & 28.148 & 1220 & 100 \\
\hline 67571 & Serenje Agro-Met & -13.227 & 30.215 & 1390 & 100 \\
\hline 67580 & Msekera & -13.646 & 32.563 & 1011 & 100 \\
\hline 67581 & Chipata & -13.564 & 32.589 & 1025 & 100 \\
\hline 67583 & Lundazi & -12.294 & 33.175 & 1138 & 100 \\
\hline 67599 & Mfuwe & -13.255 & 31.931 & 557 & 81.68 \\
\hline 67633 & Mongu & -15.254 & 23.151 & 1048 & 100 \\
\hline 67641 & Kaoma & -14.795 & 24.804 & 1158 & 100 \\
\hline 67655 & Mumbwa & -15.078 & 27.189 & 1209 & 96.67 \\
\hline 67659 & Kafue Polder & -15.777 & 27.921 & 976 & 86 \\
\hline 67662 & Kabwe Agro-Met & -14.395 & 28.828 & 1175 & 92 \\
\hline 67663 & Kabwe Met & -14.448 & 28.302 & 1204 & 100 \\
\hline 67665 & Lusaka Int. Airport & -15.324 & 28.448 & 1153 & 100 \\
\hline 67666 & Lusaka City Airport & -15.417 & 28.321 & 1274 & 91.68 \\
\hline 67667 & Mt. Makulu & -15.548 & 28.248 & 1221 & 100 \\
\hline 67673 & Petauke & -14.251 & 31.339 & 1022 & 100 \\
\hline 67731 & Senanga & -16.111 & 23.298 & 1012 & 88.32 \\
\hline 67741 & Sesheke & -17.477 & 24.301 & 942 & 92 \\
\hline 67743 & Livingstone & -17.823 & 25.82 & 991 & 100 \\
\hline 67751 & Magoye & -15.998 & 27.617 & 1025 & 86.21 \\
\hline 67753 & Choma & -16.838 & 27.07 & 1275 & 100 \\
\hline 67754 & Chipepo & -16.795 & 27.879 & 488 & 88 \\
\hline
\end{tabular}

Obs freq is the frequency of observations as a percentage
(2015) was also used. This data set is a result of the combined effort of the University of California and the United States Geological Survey (USGS). The data set covers latitudes $50^{\circ} \mathrm{S}-50^{\circ} \mathrm{N}$ and all longitudes. CHIRPS is a merge of $0.05^{\circ} \times 0.05^{\circ}$ resolution satellite imagery and in situ gauge data. The satellite imagery is sourced from the Globally Gridded Satellite (GridSat) data set of the National Climate Centre of NOAA. As in ARCv2, in situ gauge data are sourced from the GTS. Some in situ gauge data are also contributed by the Southern Africa Service Centre for Climate Change and Adaptive Land Management (SASSCAL), Global Historical Climate Network (GHCN), and the Global Summary of the Day (GSOD). A detailed description of this data set is available in the work of Funk et al. (2015) and here: https://chg.geog.ucsb.edu/data/chirps/.

\section{TAMSATv3}

TAMSATv3 (Tropical Applications of Meteorology using Satellite and ground-based observations), a product of the University of Reading was also evaluated in this study. It is gridded at a spatial resolution of $0.0375^{\circ} \times 0.0375^{\circ}$ and covers the period 1983 to near-present. The primary sources of data for the development of TAMSAT are the Meteosat IR imagery from EUMETSAT and rainfall data from in situ rain gauges. The Meteosat imagery used was retrieved every 
$30 \mathrm{~min}$ prior to mid-2006 and every $15 \mathrm{~min}$ thereafter. Maidment et al. (2017) describes this data set in detail. Further information can also be found online at: https://www.tamsa t.org.uk/data/archive.

\section{PERSIANN}

Precipitation Estimation from Remotely Sensed Information using Artificial Neural Networks-Climate Data Record (PERSIANN; Ashouri et al. 2015) was also examined. PERSIANN is a product of the National Climatic Data Center (NCDC), a technical organ of NOAA. This product is gridded at a spatial resolution of $0.25^{\circ} \times 0.25^{\circ}$ covering latitudes $60^{\circ} \mathrm{S}$ and $60^{\circ} \mathrm{N}$ and all longitudes. The data set is available for the period 1983 to near-present. PERSIANN is a direct product of an artificial neural network model. To calibrate the model, hourly precipitation data were sourced from the National Center for Environment Prediction (NCEP) and to run it, IR imagery was sourced from GridSat. The final product was bias corrected using the Global Precipitation Climatology Project (GPCP) data set. The work of Ashouri et al. (2015) describes this data set in detail with additional information provided online at: https://climatedataguid e.ucar.edu/climate-data/persiann-cdr-precipitation-estim ation-remotely-sensed-information-using-artificial.

\section{Statistical methodologies}

The comparative methods employed herein involved the use of SRPs for only the grid cells containing rain gauges. To avoid augmenting errors, stations that had less than $80 \%$ observational frequency were excluded. SRPs data for these stations were also not considered. This brought the total number of stations that were used for further analyses to 35. The geographical location of these stations together with their elevation and frequency of observations is given in Table 1.

The 35 stations were then subjected to a standard normal homogeneity test (SNHT) with the aim of removing any influence that may have been exerted by inhomogeneities. Inhomogeneous data can be a result of changes in measurement approaches, changes in instrumentation or location of observatory stations. Although, there are many methods of testing homogeneity, SNHT is the commonly used method in hydrometeorological research (Alexandersson et al. 1997). Mathematically, SNHT is given as:

$T_{y}=y \overline{z_{1}}+(n-y) \overline{z_{2}}, \quad y=1,2, \ldots, n$

where: $\overline{z_{1}}=\frac{1}{y} \sum_{i=1}^{n} \frac{\left(Y_{i}-\overline{Y)}\right.}{S}$ and $\overline{z_{2}}=\frac{1}{n-y} \sum_{i=y+1}^{n} \frac{\left(Y_{i}-\overline{Y)}\right.}{S}$

$T_{y}$ is a statistic which is used to compare the mean of the first $y$ years with the last of $(n-y)$ years. $\overline{Z_{1}}$ and $\overline{Z_{2}}$ are the values of $\bar{Z}_{i}$ during the first $y$ years and the last $(n-y)$ years, respectively. If the value of $T$ is maximum, the year of $y$ would be considered as having a break. The null hypothesis is rejected if the test

$T_{0}=\max _{1 \leq y \leq n} T_{y}$

is greater than the critical value, which is dependent on the size of the sample under consideration (Kang et al. 2012). The hypothesis was tested at $\alpha=0.05$ as follows:

$H_{0}$ is the Data are homogeneous, $H_{a}$ is the there is a date at which there is a change in the data.

As part of data preparation and before any comparative analyses were done, Climate Data Operators (CDO) were employed in which Kriging was used as in Oliver et al. (1990) to temporally fill in the blanks of missing values. The temporal interpolation was done so that data sets with missing values e.g. ARCv2 would not be disadvantaged during comparative analysis. Although there are many other interpolation methods, Kriging was chosen because previous literature (see for example: Creutin et al. 1982; Tabios et al. 1985; Goovaerts 2000; Maidment et al. 2017) found it to be superior over other forms of interpolation. Kriging weights the surrounding measured values to derive a prediction for an unmeasured location. The general formula for kriging is given as:

$\hat{\mathrm{Z}}\left(s_{o}\right)=\sum_{i=1}^{n} \lambda_{i} Z\left(s_{i}\right)$

where $\mathrm{Z}\left(s_{i}\right)$ is the measured value at the $i$ th location; $\lambda_{i}$ is an unknown weight for the measured value at the $i$ th location; $s_{0}$ is the predicted location and $N$ is the number of measured values.

Coefficient of determination $\left(R^{2}\right)$ was also explored to quantify the magnitude of how closely SRPs follow rain gauge data. $R^{2}$ is mathematically defined as the regression sum of squares divided by the total sum of squares and is expressed as:

$R^{2}=1-\frac{S S_{\text {res }}}{S S_{\text {tot }}}$

where $S S_{\text {res }}$ is the residual sum of squares and $S S_{\text {tot }}$ is the total sum of squares with respect to the variance of the data. The grading of $R^{2}$ varies between 0 and 1 with 0 denoting that the predictor variable does not explain any of the 


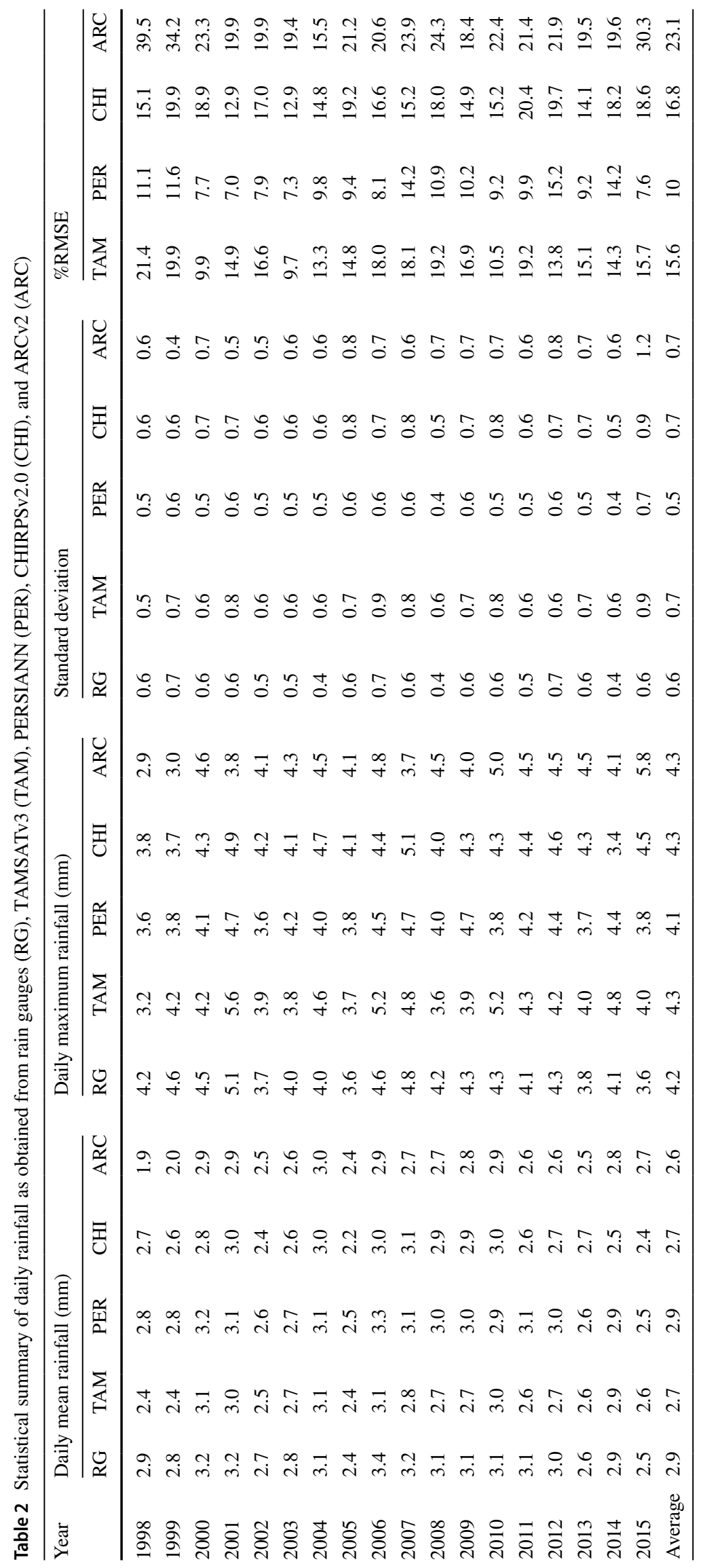


variation in the dependant variable, while 1 shows that the predictor variable accounts for all of the variation in the dependant variable (Basheer and Elagib 2018).

We further employed percent root-mean-square error (\%RMSE) as used by Duan et al. (2012), to examine the reliability of SRPs against rain gauge data. Basically, \%RMSE returns values lower than $50 \%$ if the data are reliable and greater than $50 \%$ if found unreliable. Mathematically, RMSE is expressed as:

$R M S E=\sqrt{\frac{\sum_{i=1}^{n}\left(X_{o b s, i}-X_{m o d e l, i}\right)^{2}}{n}}$

here $X_{o b s}$ is rain gauge data and $X_{\text {model }}$ are the SRP data sets at time/place $i$ (Chai et al. 2014). To calculate \% RMSE, we divided the RMSE by the mean of rain gauge data. This approach is also available in the work of Duan et al. (2012) who studied the ability of Tropical Rainfall Measurement Mission (TRMM) to simulate rain gauge data in the Caspian Sea Region.
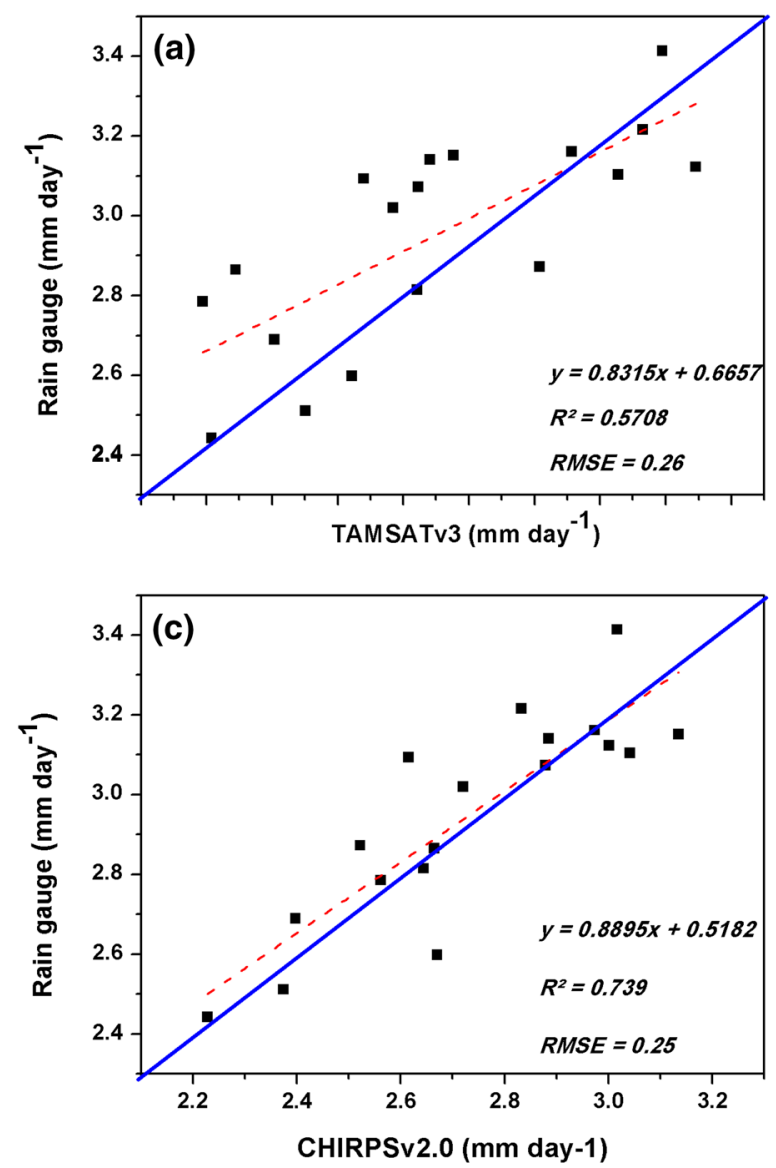

Fig. 2 Scatter plot of the average daily rainfall on an annual basis for rain gauge and SRPs data over Zambia, averaged over longitude $21.8^{\circ} \mathrm{E}-34^{\circ} \mathrm{E}$ and latitudes $18^{\circ} \mathrm{S}$ and $8^{\circ} \mathrm{S}$ for the period $1998-2015$.
We employed two more statistical measures for annual rainfall estimates; these are the coefficient of variation $(\mathrm{CV})$ and the median (M). The median is best defined as a measure of central tendency while the $\mathrm{CV}$ is the ratio of the standard deviation to the mean and as such a good measure of dispersion. It can take any value from zero variability to high variability. Mathematically, the $\mathrm{CV}$ is given as:

$C V(\%)=\frac{\sqrt{\frac{\sum_{i}^{n}\left(s_{i}-\bar{s}\right)}{n-i}}}{\bar{s}} \times 100$

where $S_{i}$ is the $i$ th rainfall estimation in mm, $n$ is the number of data pairs, and $\bar{s}$ is the average of the rainfall estimates (Basheer and Elagib 2018).

Comparisons were also done for three stations lying at the highest, middle and lowest elevations to examine the ability of SRPs to capture precipitation occurrences on complex topography. Mbala at $1665 \mathrm{~m}$, Kabwe main at $1204 \mathrm{~m}$ and Chipepo at $488 \mathrm{~m}$ were the highest, middle and lowest elevations, respectively (Table 1).
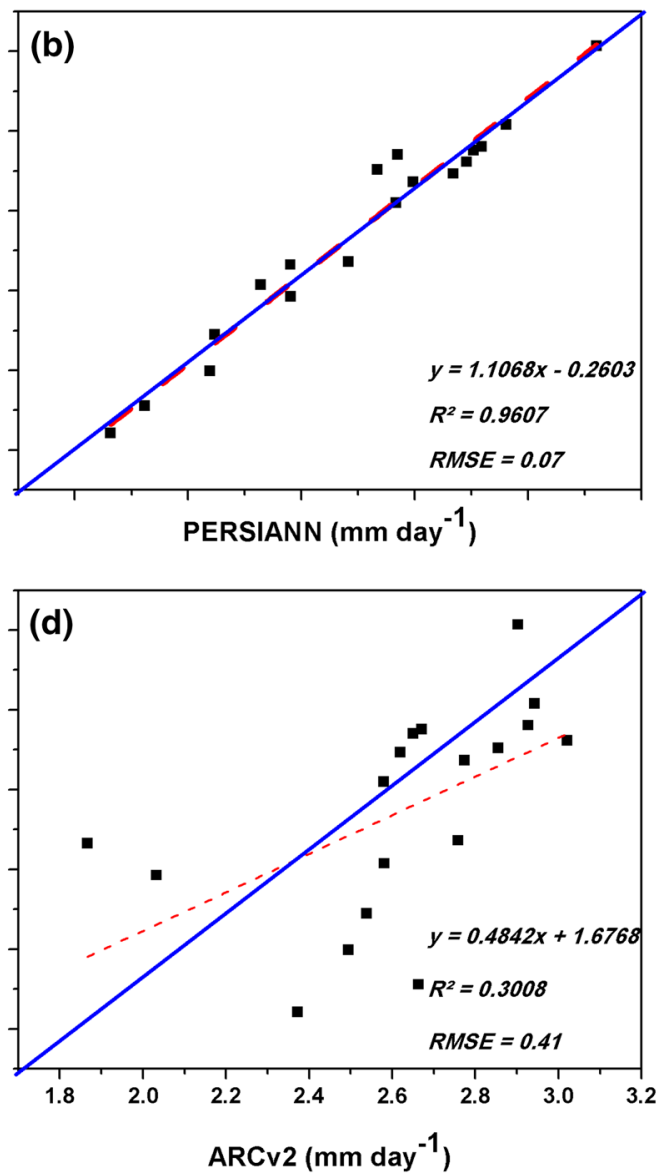

The blue solid lines represent the 1:1 while the red and dashed are the regression lines 
Methods used herein have been employed by several studies to investigate the possibility of using SRPs in data sparse regions around the world. For example, Bowman (2005) compared TRMM rainfall retrievals with rain gauge data from the TAO/TRITON buoy array. In a similar study He et al. (2017), compared daily rainfall from Global Precipitation Measurement (GPM) and TRMM over the Mekong river basin.

\section{Results and discussion}

\section{Daily rainfall}

Results of the homogeneity test showed that all stations were homogeneous apart from Lusitu, and it was therefore excluded from further analyses. Statistical results of how closely SRPs match rain gauge data are shown in Table 2. These results are presented as daily rainfall on an annual scale. Notably, SRPs were able to simulate daily means accurately with percent root-mean-square errors of lower than $50 \%$ in all cases. Figure 2 presents scatter plots of each SRP against rain gauge data. With an $R^{2}$ value of 0.96 , PERSIANN was the highest performing SRP followed by CHIRPSv2.0 and TAMSATv3.0, respectively. With an $R^{2}$ value of $0.3, \mathrm{ARCv} 2$ was the lowest performing product. RMSE results further confirm these findings with PERSIANN having lowest RMSE $(0.07 \mathrm{~mm})$ followed by CHIRPSv2.0 (0.25 mm), TAMSATv3.0 (0.26 mm) and ARCv2 $(0.41 \mathrm{~mm})$, respectively. These results suggest that experiments using daily average rainfall of PERSIANN data are expected to arrive at similar results as those using rain gauge data. The low performance found in ARCV2 has been highlighted by Novella and Thiaw (2013) who attributed it to decreased availability of in situ measurements which leads to a tendency of $\mathrm{ARCv} 2$ underestimating rain gauge data.

Although 3 of these SRPs (i.e. PERSIANN, CHIRPSv2.0, and TAMSATv3.0) were able to mimic daily mean rainfall of rain gauge data with $R^{2}$ values of $>0.5$ (Fig. 2), problems were acute with reproducing daily maxima (Fig. 3). All the SRPs did not accurately capture the daily maxima of rainfall. Therefore, caution
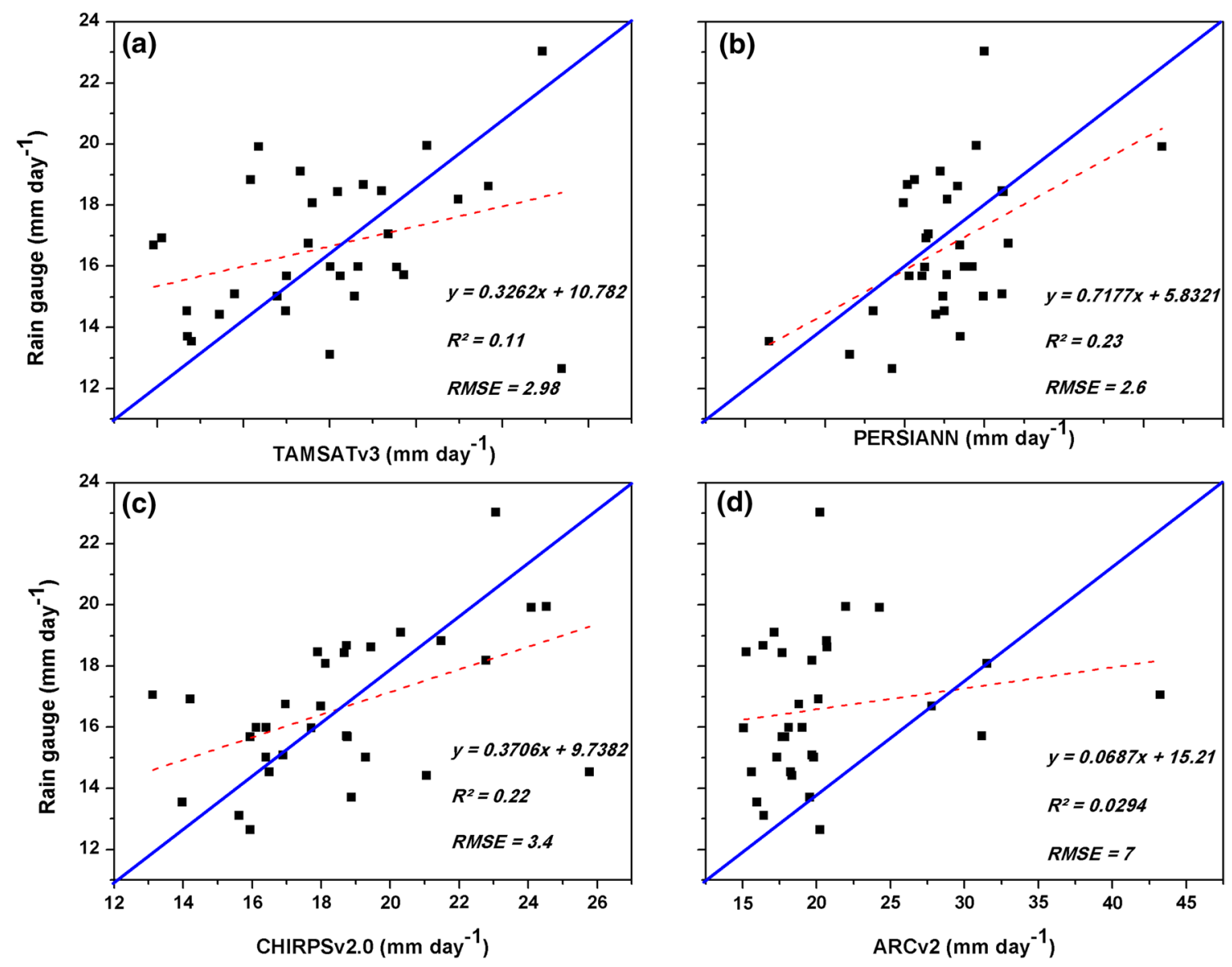

Fig. 3 Scatter plot of the maximum daily rainfall in each month for rain gauge and SRPs data over Zambia, averaged over longitude $21.8^{\circ} \mathrm{E}-34^{\circ} \mathrm{E}$ and latitudes $18^{\circ} \mathrm{S}$ and $8^{\circ} \mathrm{S}$ during the period 1998

2015. The blue solid lines represent the 1:1 while the red and dashed are the regression lines 
needs to be taken for experiments considering the use of peaks. It is highly recommended that such experiments take bias correction into account. Generally, SRPs seem to perform better on rainfall averages than maxima in the tropics. Similar results were found by Tarek et al. (2017) who assessed the performance of TRMM in Bangladesh and found good agreement on means and totals but overestimation on maximum values.

\section{Monthly rainfall}

In a developing country like Zambia, where both wet and dry spells are common (Hachigonta et al. 2006) and where most people depend on agriculture for a livelihood, a reliable understanding of monthly variations of rainfall is important. Perhaps more important than understanding the annual variations because an understanding of intraseasonal variations empowers farmers with knowledge that enables them to make informed decisions on sowing and harvesting dates (Hachigonta et al. 2008). It also furnishes hydrometeorologists with vital information for flood preparedness. For these reasons, SRPs were also analysed in terms of their ability to capture the month to month cycle of total rain gauge data. Results (Fig. 4) indicate that all the SRPs were adequately able to reproduce the bimodal rainfall cycle of Zambia with dry periods during the months of May to September and wetness from October to April.

Figure 5 presents the scatter plots of each of the four SRPs. These results indicate that all the SRPs mimicked gauge data with $R^{2}>0.9$. To rank their performance, RMSE was examined and it was found that with a value of only $4.6 \mathrm{~mm}$, PERSIANN outperformed the other 3 SRPs, followed by CHIRPSv2.0, TAMSATv3, and ARCv2, respectively. It's the finding of this study therefore, that although PERSIANN outperforms the other SRPs, they are all reliably able to be used in studies that aim at using monthly rainfall.
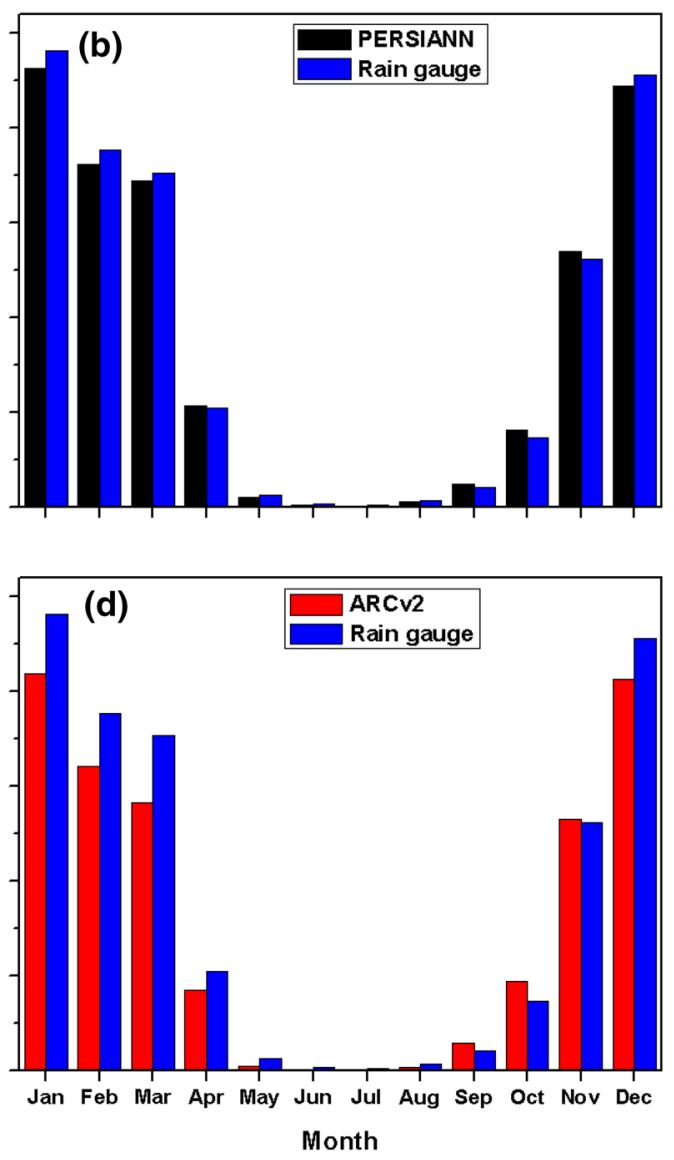

and $\mathbf{d}$ rain gauge (blue) versus ARCv2 (red), averaged over longitude $21.8^{\circ} \mathrm{E}-34^{\circ} \mathrm{E}$ and latitudes $18^{\circ} \mathrm{S}$ and $8^{\circ} \mathrm{S}$ during the period 1998 2015
Fig. 4 Average monthly rainfall over Zambia for: a rain gauge (blue) versus TAMSATv3 (grey), b rain gauge (blue) versus PERSIANN (black), c rain gauge (blue) versus CHIRPSv2.0 (orange)
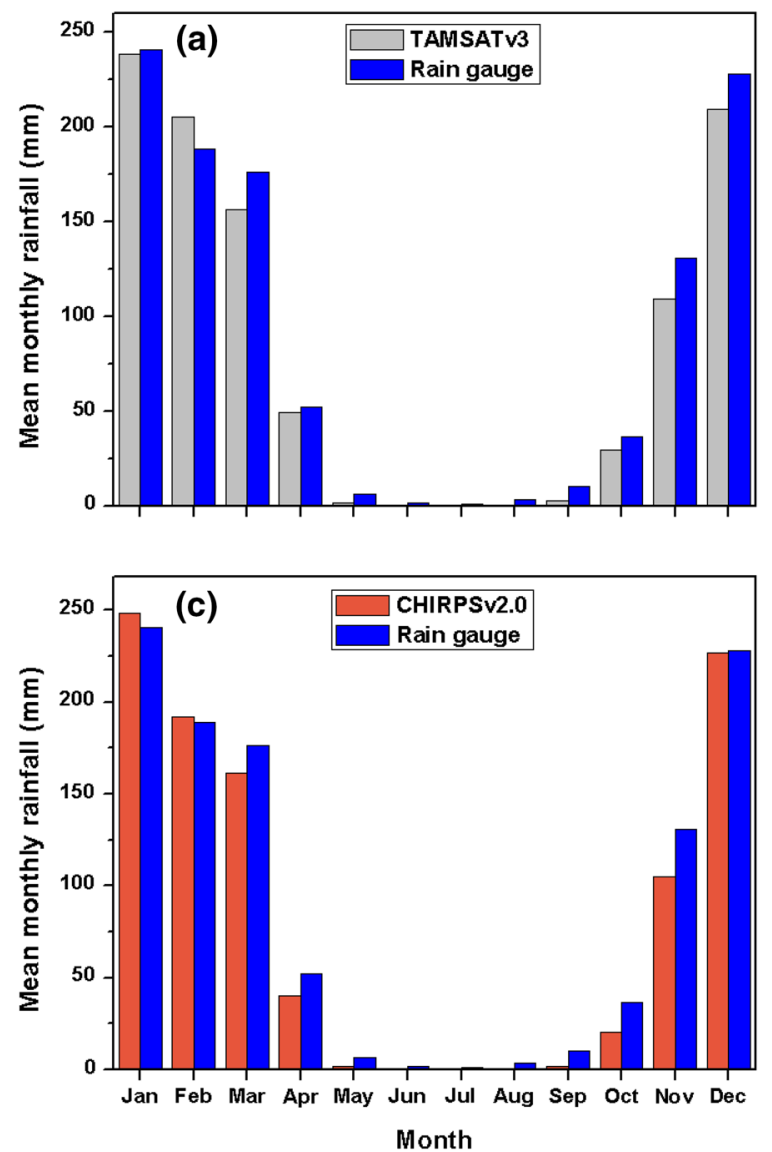

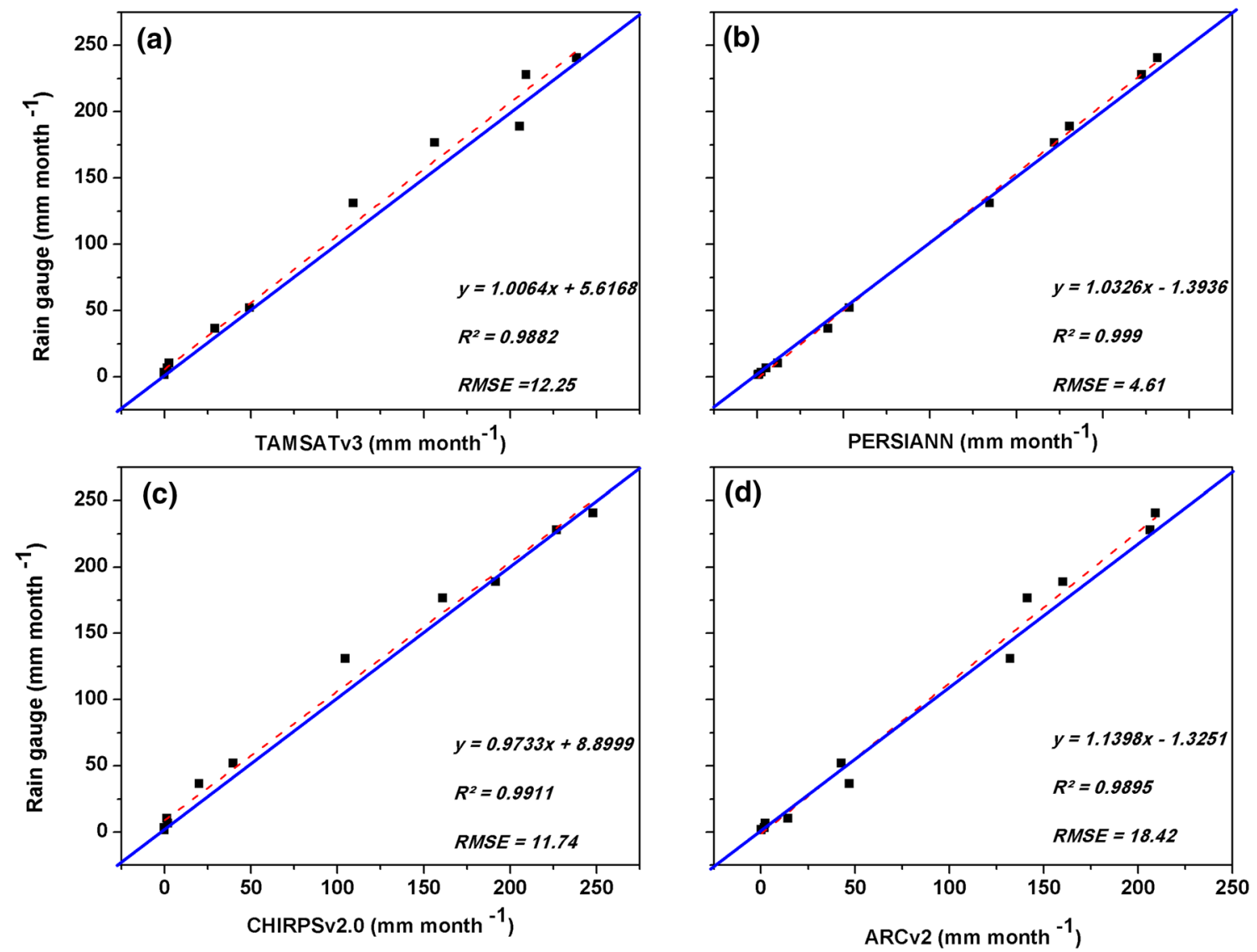

Fig. 5 Scatter plot of mean monthly rainfall over Zambia for: a rain gauge versus TAMSATv3, b rain gauge versus PERSIANN, $\mathbf{c}$ rain gauge versus CHIRPSv2.0, d rain gauge versus ARCv2, averaged

over longitude $21.8^{\circ} \mathrm{E}-34^{\circ} \mathrm{E}$ and latitudes $18^{\circ} \mathrm{S}$ and $8^{\circ} \mathrm{S}$ during the period 1998-2015. The blue solid lines represent the 1:1 while the red and dashed are the regression lines

\section{Seasonal rainfall}

Even though rains in the dry season are not common, some occasional precipitation activities especially in the winter are experienced in Zambia. Exploratory analyses of rain gauge data further showed that these rains usually amount to less than a millimetre (trace) in $24 \mathrm{~h}$ but can accumulate up to $20 \mathrm{~mm}$ over the entire dry season. Dry seasons invariably experience sporadic showers over Zambia especially if they follow a strong La Nina which tends to deposit excess moisture over the country.

SRPs were therefore investigated on how closely they follow gauge data during the wet and dry seasons. Results (Fig. 6 left panel) show that these products and rain gauge data are strongly correlated during the wet season with an $R^{2}>0.5$ in all cases except ARCv2 which scored only 0.29. However, the occasional localised rains that fall during the dry season were poorly captured by all SRPs (Fig. 6 right panel) with $R^{2}<0.5$ except PERSIANN which scored $\sim 0.8$. The observed $R^{2}$ values are also in agreement with RMSE values i.e. well performing products score high on $R^{2}$ but low on RMSE. Taken together, PERSIANN outperforms all products followed by CHIRPSv2.0, TAMSATv3 and ARCv2, respectively.

\section{Annual rainfall}

SRPs were also examined on their ability to capture variability on an annual basis for the period 1998-2015. Results (Fig. 7) show that all the products were generally able to pick the curves and inter-annual variations of gauge data. It is worth noting that apart from $\mathrm{ARCv} 2$, all products detected a downward trend in annual precipitation. At the station level, the trend of annual rainfall is variable, with marginal upward trends generally being statistically insignificant (Chabala et al. 2013) but taken together over Zambia, there is a statistically significant downward trend (Libanda et al. 2018). The inability of ARCv2 to reproduce the decreasing trend of annual rainfall over Zambia is again reflected in the $R^{2}$ value as it is the only product with a value less than 0.5 and RMSE greater than $100 \mathrm{~mm}$ (Fig. 8d). 
Rainy season (Oct - Apr)

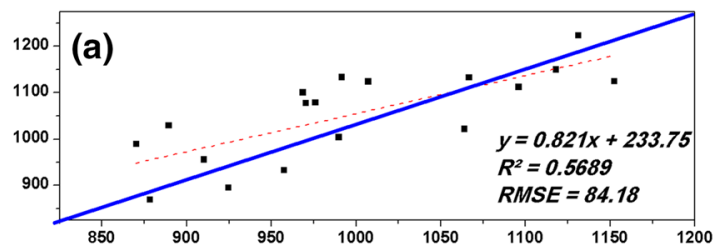

Dry Season (May - Sep)

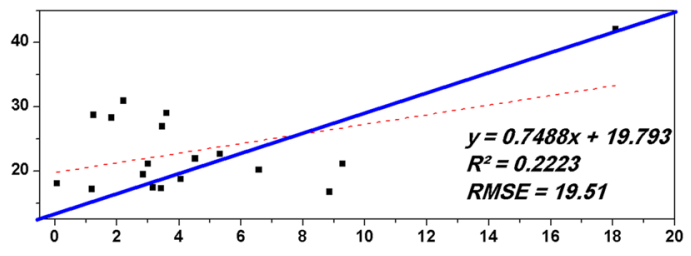

TAMSATv3 (mm)
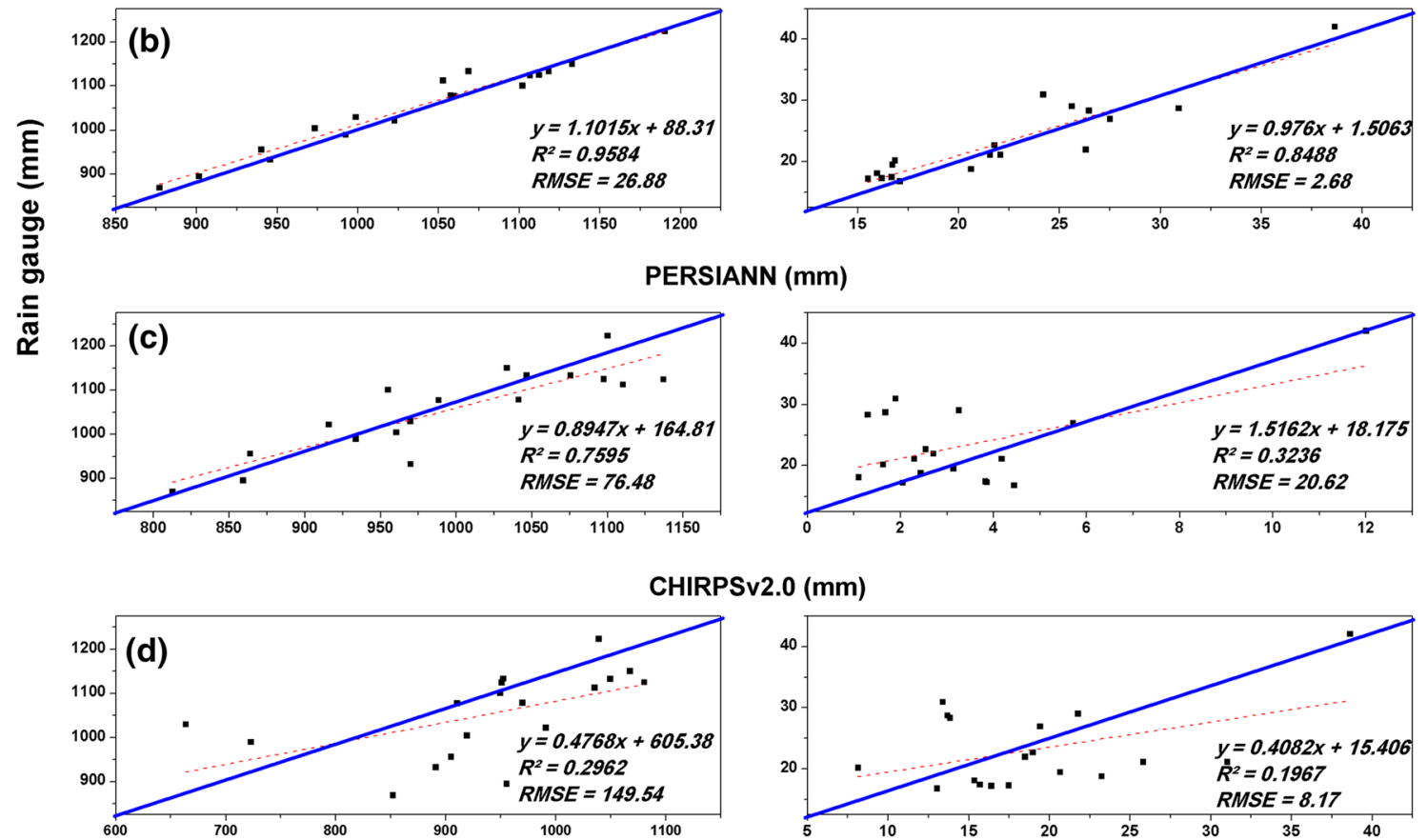

PERSIANN (mm)

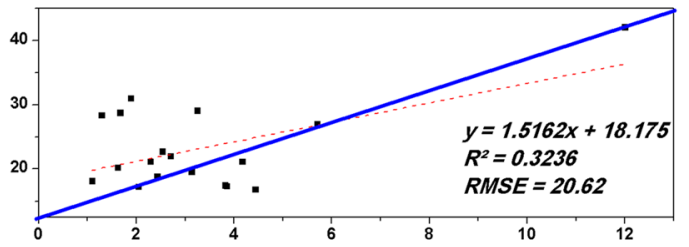

HIRPSv2.0 (mm)

ARCv2 (mm)

Fig. 6 Scatter plot of seasonal rainfall over Zambia for left panel, rainy season and right panel, dry season, averaged over longitude $21.8^{\circ} \mathrm{E}-34^{\circ} \mathrm{E}$ and latitudes $18^{\circ} \mathrm{S}$ and $8^{\circ} \mathrm{S}$ during the period 1998

It is notable that although the performance of SRPs at seasonal (Fig. 6) and annual (Fig. 8) scales is similar, $R^{2}$ values of annual rainfall compared to seasonal rainfall are lowered slightly while RMSE values increase owing to the general poor performance of SRPs during dry season.

Given the surprising results in terms of annual rainfall trend direction exhibited by ARCv2 (Fig. 7), two more statistical measures, coefficient of variation $(\mathrm{CV})$ and median (M), were employed to assess all the SRPs at annual scales. $\mathrm{CV}$ is a measure of dispersion while median is a measure of central tendency when dealing with variable rainfall (Ananthakrishnan and Soman 1989). These statistical measures are widely used in validation studies of SRPs. For example, recently, Basheer and Elagib (2018) employed them to validate SRPs in a data-scarce South Sudan. In this study, our findings (Table 3 ) indicate that PERSIANN outperforms all the other products. CHIRPSv2.0 is rated second followed by TAMSATv3 and lastly ARCv2.
2015. The blue solid lines represent the $1: 1$ while the red and dashed are the regression lines

SRPs were further studied on their ability to capture annual extreme events. This was done by removing influences of dispersion, computing and plotting normalised anomalies of both SRPs and rain gauge observations. Many studies have argued that normalised anomalies are a useful measure of how intense an event was (Ogwang et al. 2012; Chanda and Maity 2015; Libanda et al. 2019). Results (Fig. 9) show that all the SRPs are generally able to mimic the direction better than the magnitude. Rain gauges show that during the period 1998-2015, Zambia received 2 extreme wet events i.e. rainfall $\geq 1$ and 4 extreme dry events i.e. $\leq-1$. The extreme wet years were 2000 and 2006 while 2002, 2005, 2013, and 2015 were generally extremely dry. We found that PERSIANN is the only data set that captures this pattern correctly. Other data sets e.g. ARCv2 and CHIRPSv2.0 show mixed signals; in some years, e.g. 2013, they underestimate rain gauge data by $\sim 50 \%$ while in others, e.g. 2001, they overestimate it. TAMSATv3 tends to 


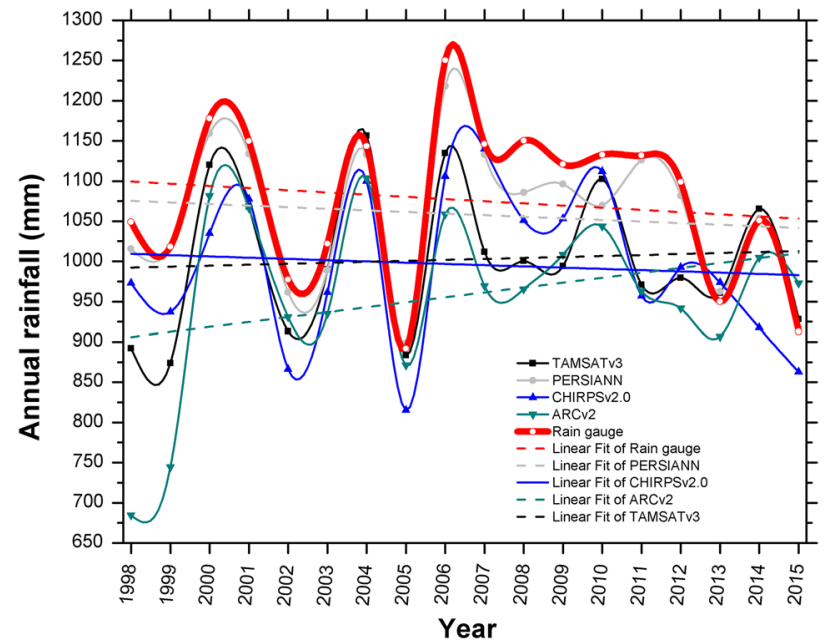

Fig. 7 Comparison of annual rainfall over Zambia for rain gauge data (thick red curve), TAMSATv3 (black), PERSIANN (grey), CHIRPSv2.0 (blue), and ARCv2 (green), averaged over longitude $21.8^{\circ} \mathrm{E}-34^{\circ} \mathrm{E}$ and latitudes $18^{\circ} \mathrm{S}$ and $8^{\circ} \mathrm{S}$ during the period 1998 2015 overestimate rain gauges. For example, in 2004, it detects an extreme wet event while rain gauge data and PERSIANN do not. The tendency of TAMSATv3 to overestimate rain gauges mirrors the findings of other studies around the world that have highlighted that generally some SRPs overestimate rain gauge data which results in false alarms (Nasrollahi 2015). This is why many studies (e.g. Shen et al. 2010; AghaKouchak et al. 2012) have devoted time to the validation of satellite-based precipitation observations.

Overall, these findings indicate that PERSIANN, CHIRPSv2.0 and TAMSAT (in order of suitability) are suitable substitutes for rain gauge data for studies that are interested in mean annual rainfall variability over Zambia. Additionally, studies aiming at understanding annual extremes over the country would arrive at similar results as rain gauge data if they employed PERSIANN.

\section{Complex topography}

Generally, Zambia is a high plateau (Haberyan 2018). Much of the landmass falls between 910 and $1370 \mathrm{~m}$ above sea

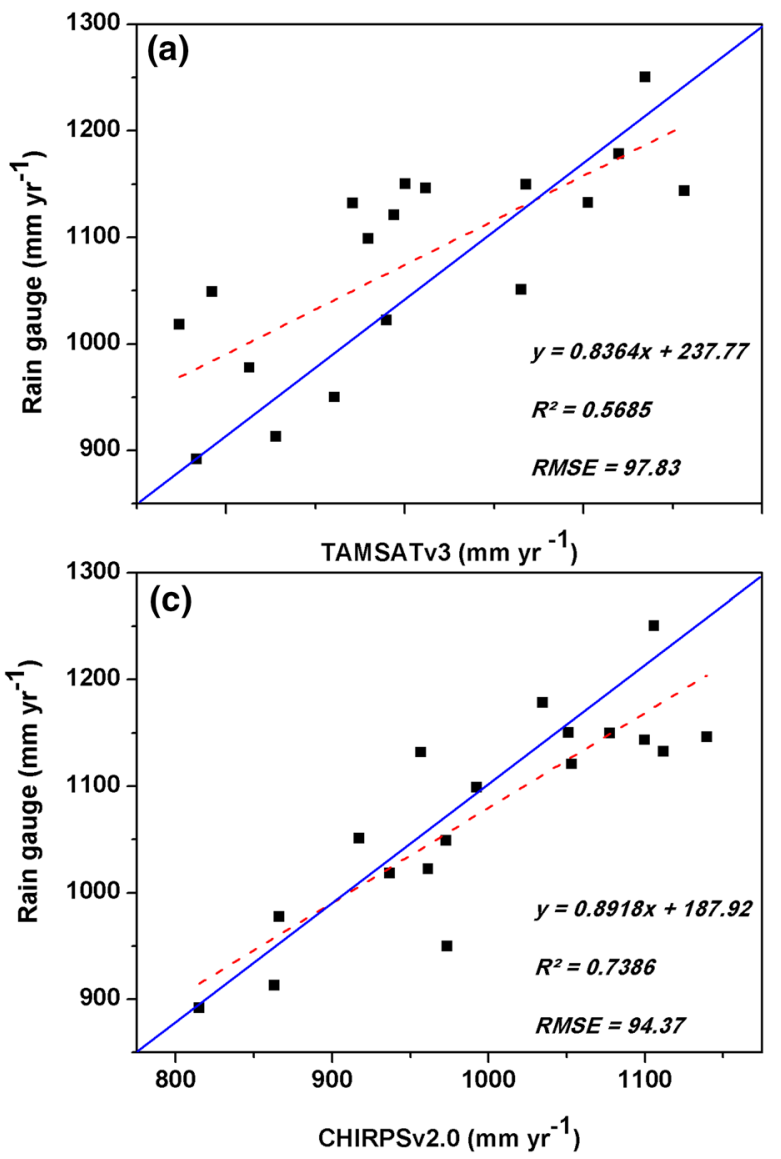

Fig. 8 Scatter plot of annual rainfall over Zambia over Zambia for left panel, rainy season and right panel, dry season, averaged over longitude $21.8^{\circ} \mathrm{E}-34^{\circ} \mathrm{E}$ and latitudes $18^{\circ} \mathrm{S}$ and $8^{\circ} \mathrm{S}$ during the period
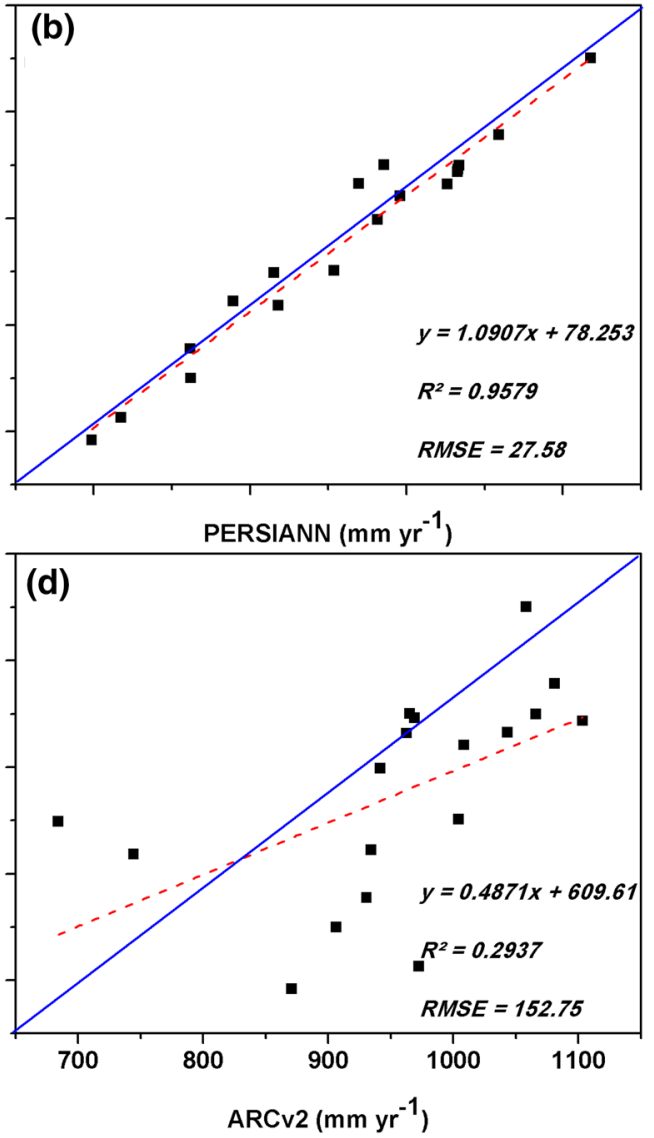

1998-2015. The blue solid lines represent the 1:1 while the red and dashed are the regression lines 
Table 3 Coefficient of variation (CV) and median (M) for SRPs and rain gauge data, averaged over longitude $21.8^{\circ} \mathrm{E}-34^{\circ} \mathrm{E}$ and latitudes $18^{\circ} \mathrm{S}$ and $8^{\circ} \mathrm{S}$ during the period $1998-2015$

\begin{tabular}{lccccc}
\hline & TAMSATv3 & PERSIANN & CHIRPSv2.0 & ARCv2 & Rain gauge \\
\hline CV $(\%)$ & 8.8 & 9 & 9.4 & 11.3 & 9.1 \\
Median $(\mathrm{mm})$ & 992.11 & 1075.69 & 993.19 & 967.26 & 1109.82 \\
\hline
\end{tabular}

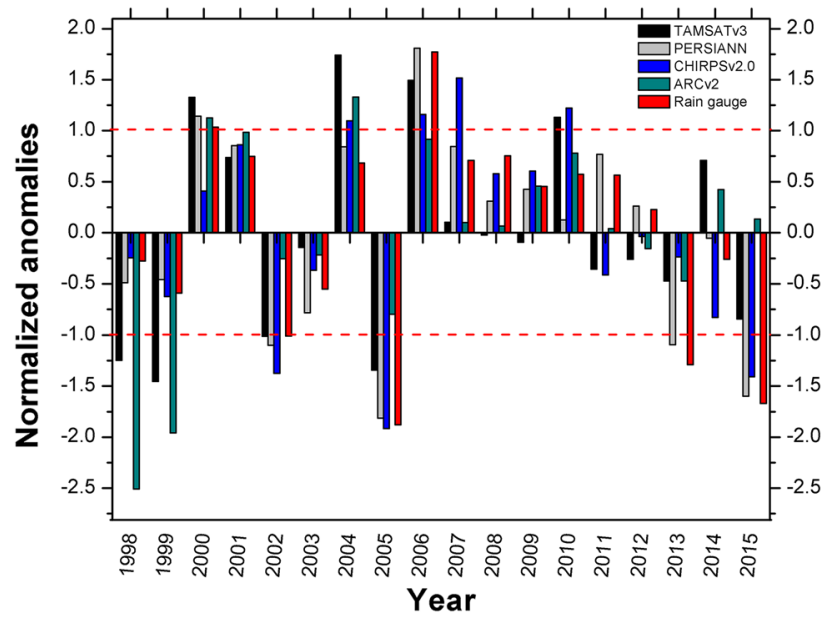

Fig. 9 Normalised anomalies for TAMSATv3 (black), PERSIANN (grey), CHIRPSv2.0 (blue), ARCv2 (green), and rain gauge (red), averaged over longitude $21.8^{\circ} \mathrm{E}-34^{\circ} \mathrm{E}$ and latitudes $18^{\circ} \mathrm{S}$ and $8^{\circ} \mathrm{S}$ during the period 1998-2015

level. However, a few areas lie outside this range; for example, areas about the Muchinga escarpment in the central province of Zambia exceed $1800 \mathrm{~m}$. Some areas along the major rivers and in valleys lie below $500 \mathrm{~m}$. This is evident in the north-eastern parts of the country were the high flat land is punctuated by the low-lying areas about the Luangwa river and in the southwestern portions of the country where the low-lying areas of the Kafue river punctuate the plateau. These two rivers flow from the Zambezi river which is the biggest watercourse in the country (Huygen 1989).

Precipitation is one of the most difficult meteorological variables to accurately quantify over rough terrain because of the contributions of convective and topographic influences. In high elevations, airflow gets altered and the amount of sunlight reaching the earth's surface differs markedly within short distances; consequently, precipitation tends to be boosted in some areas and suppressed in others. This has been collaborated by other studies like Ogwang et al. (2014) who used the International Centre for Theoretical Physics Regional Climate Model to study the influence of topography on East African October to December Climate. Their findings indicated that generally mean rainfall tended to reduce with a reduction in topography while temperature was observed to generally increase.
SRPs were therefore, investigated on their ability to capture rain gauge data over varying topography. Three stations at the highest, medium and lowest topography were selected and used to carry out this analysis. These stations are Mbala at $1665 \mathrm{~m}$, Kabwe main at $1204 \mathrm{~m}$ and Chipepo at $488 \mathrm{~m}$ (Table 2). Results (Fig. 10) indicate that there is reliable capturing of all the curves at all stations. The wetter months of November-April and the drier months of May-October were accurately captured by all data sets. When $R^{2}$ and RMSE metrics are taken into consideration, PERSIANN outperforms all the other SRPs. However, $R^{2}$ of all the SRPs is greater than 0.9 . This reaffirms the results highlighted in Fig. 5 that generally all the SRPs perform well at capturing the monthly cycle of precipitation.

These results further indicate that spatially, SRPs can adequately mimic rain gauge data. The spatial patterns also indicate that SRPs can accurately capture the drier areas of the southern parts of the country and the wetter northern half as observed by rain gauges and collaborated by previous studies (e.g. Hachigonta et al. 2008). This precipitation pattern is a major concern for hydrologists mainly because Lake Kariba, the world's largest man-made lake by volume and Zambia's main source of hydroelectricity, is located in the southern part of the country (Libanda et al. 2019). Therefore, the ability of SRPs to pick this precipitation pattern shows that they can among other things, be used for observational and modelling studies that seek to enhance hydrologic impact assessments on hydroelectricity production.

\section{Concluding remarks}

The traditional means of rainfall estimation has always been the use of rain gauges. While their advantage of direct precipitation measurements is well documented (Stampoulis et al. 2013), they are often found to be of low density hence of poor spatial resolution. The inherent nature of these point-based gauges inhibits the capturing of the intensity and frequency of precipitation in unmeasured areas. Their uncertainty is also compounded by possible human errors and the effects of wind.

The advent of satellites-based rainfall products (SRPs) has to some extent addressed this problem. However, SRPs are not short of errors and uncertainties. Therefore, they 


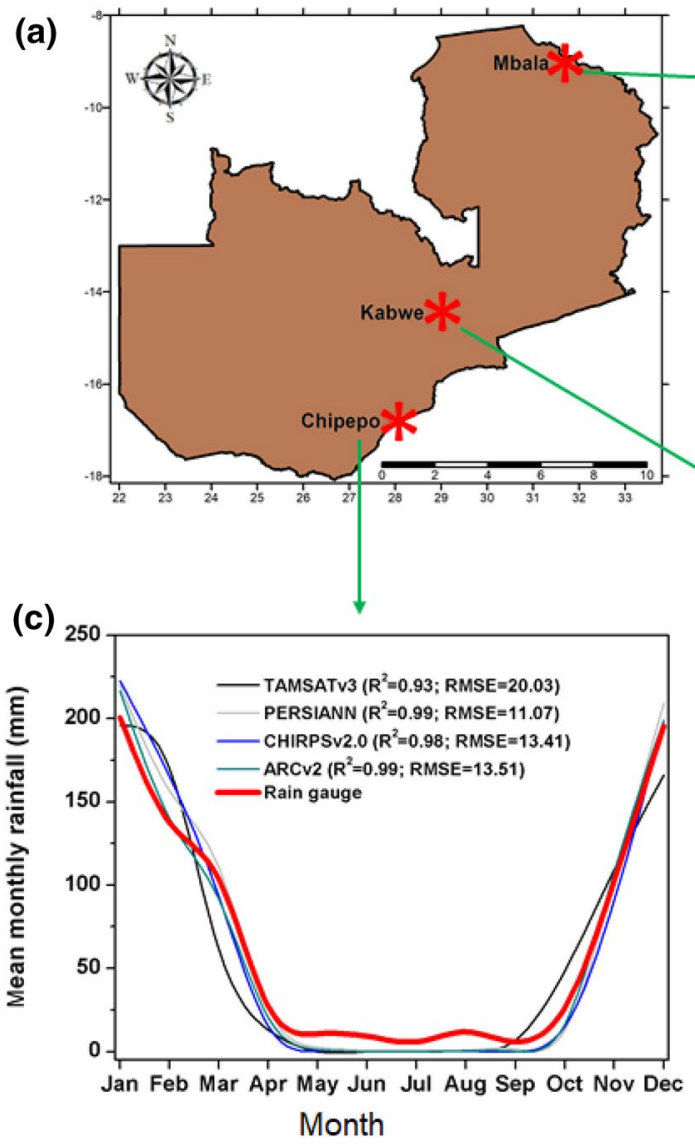

(b)

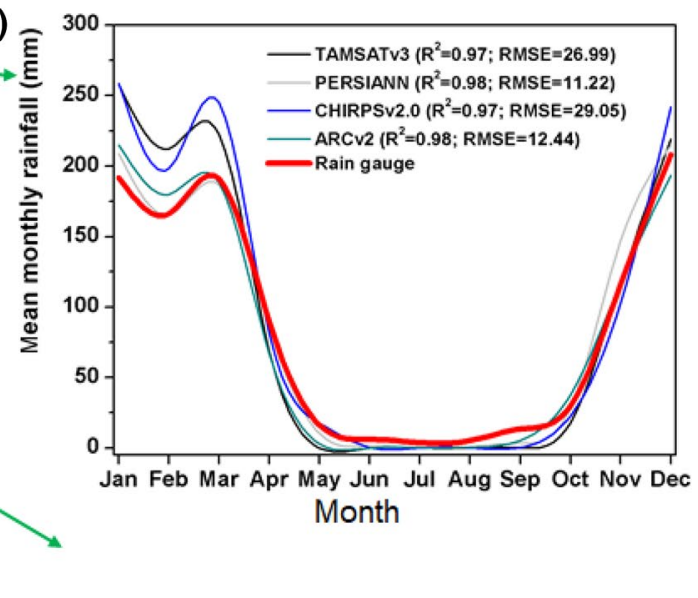

(d)

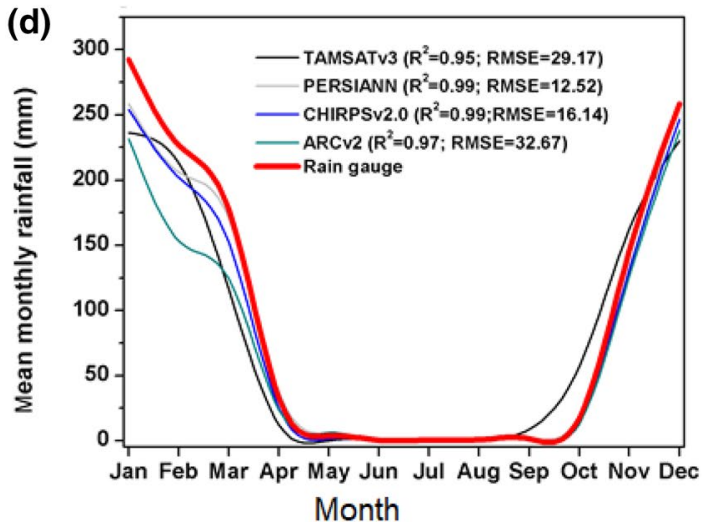

Fig. 10 Mean monthly rainfall for TAMSATv3 (black), PERSIANN (grey), CHIRPSv2.0 (blue), ARCv2 (green), and rain gauges (red) for the period 1998-2015. Where a shows the geographical location of the stations considered b Mbala, $\mathbf{c}$ Kabwe, d Chipepo

are better used following an extensive validation process (Scofield and Kuligowski 2003; Amitai et al. 2012; Derin et al. 2014; Janjai et al. 2015; Oreggioni et al. 2018). Zambia like many other developing countries is a highly data-scarce country with few and unevenly distributed meteorological stations. To this end, this study set out to investigate the skill of 4 SRPs (i.e. TAMSATv3.0, PERSIANN, CHIRPSv2.0, and ARCv2) in capturing precipitation patterns as observed by 35 rain gauges doted all over Zambia. The goal of the comparative analysis was to examine SRPs' ability to be used in rain gauge sparse regions of Zambia. Several temporal scales were used for the comparative analysis and they include daily, monthly, seasonal and annual. Investigations were also done on how well SRPs mimic rain gauge data in terms of average, maxima and total precipitation. A comparative analysis of SRPs and gauge data over a multifaceted terrain was also done to investigate their ability to capture rainfall variations over complex topography.

Results indicate that all the 4 SRPs adequately match rain gauge data at monthly scales even on complex topography. Taken together, the coefficient of determination between the individual SRPs and gauge data is generally $>0.9$ at monthly scales. However, the ability of these products to capture rain gauge data at daily, seasonal and annual scales differs markedly. Specifically, PERSIANN outperforms all the other SRPs at all scales, CHIRPSv2.0 is rated second, followed by TAMSATv3 and ARCv2, respectively. These results suggest that PERSIANN can be used, reliably, in studies that seek to estimate rainfall in data sparse regions of Zambia. It is however worth noting the differences highlighted in this work and for optimum results, applying calibrations at the local scale.

While this study has shown the suitability of using PERSIANN as a substitute for daily rainfall measurements in Zambia, the enhancement and improvement of meteorological station networks is still imperative. Further, while results embodied in this work are useful for the case of Zambia, they cannot be generalised to other regions. This is because generally, the behaviour of SRPs differs from one region to the other (Zeng et al. 2018).

Acknowledgements The first Author carried out this work while on a $\mathrm{PhD}$ funded by the University of Edinburgh; the university is hereby acknowledged for the financial support, for creating an environment 
that nurtures research activities, and for some of the statistical facilities used during data analysis. The Editor and the 3 anonymous Reviewers are acknowledged for their invaluable feedback. The Zambia Meteorological Department (ZMD), the Climate Prediction Centre, the Climate Hazards Group, the University of Reading, and the National Climatic Data Center (NCDC) are acknowledged for the data sets used in this study.

\section{Compliance with ethical standards}

Conflict of interest On behalf of all authors, the corresponding author states that there is no conflict of interest.

Open Access This article is licensed under a Creative Commons Attribution 4.0 International License, which permits use, sharing, adaptation, distribution and reproduction in any medium or format, as long as you give appropriate credit to the original author(s) and the source, provide a link to the Creative Commons licence, and indicate if changes were made. The images or other third party material in this article are included in the article's Creative Commons licence, unless indicated otherwise in a credit line to the material. If material is not included in the article's Creative Commons licence and your intended use is not permitted by statutory regulation or exceeds the permitted use, you will need to obtain permission directly from the copyright holder. To view a copy of this licence, visit http://creativecommons.org/licenses/by/4.0/.

\section{References}

AghaKouchak A, Mehran A, Norouzi H, Behrangi A (2012) Systematic and random error components in satellite precipitation data sets. Geophys Res Lett 39:9. https://doi.org/10.1029/2012GL051592

Agnihotri G, Dimri AP (2015) Simulation study of heavy rainfall episodes over the southern Indian peninsula. Meteorol Appl 22:223-235. https://doi.org/10.1002/met.1446

Alexandersson H, Moberg A (1997) Homogenization of Swedish temperature data. Part I: homogeneity test for linear trends. Int J Climatol 17:25-34

Amitai E, Unkrich L, Goodrich D, Habib E, Thill B, Thill B (2012) Assessing satellite-based rainfall estimates in semiarid watersheds using the USDA-ARS walnut gulch gauge network and trmm PR. J Hydrometeorol 13:1579-1588. https://doi. org/10.1175/JHM-D-12-016.1

Ananthakrishnan R, Soman MK (1989) Statistical distribution of daily rainfall and its association with the coefficient of variation of rainfall series. Int J Climatol 9:485-500. https://doi. org/10.1002/joc.3370090504

Ashouri H, Hsu K, Sorooshian S, Braithwaite D, Knapp K, Cecil D, Nelson B, Prat O (2015) PERSIANN-CDR: daily precipitation climate data record from multisatellite observations for hydrological and climate studies. Bull Am Meteorol Soc 96:69-83. https://doi.org/10.1175/BAMS-D-13-00068.1

Awange JL, Ferreira VG, Forootan E, Khandu Andam-Akorful SA, Agutu NO, He XF (2016) Uncertainties in remotely sensed precipitation data over Africa. Int J Climatol 36:303-323. https:// doi.org/10.1002/joc.4346

Bajracharya SR, Palash W, Shrestha MS, Khadgi VR, Duo C, Das PJ, Dorji C (2015) Systematic evaluation of satellite-based rainfall products over the Brahmaputra Basin for hydrological applications. Adv Meteorol 2015:1-17. https://doi. org $/ 10.1155 / 2015 / 398687$

Basheer M, Elagib NA (2018) Performance of satellite-based and GPCC 70 rainfall products in an extremely data-scarce country in the Nile Basin. Atmos Res. https://doi.org/10.1016/j.atmos res.2018.08.028

Becker J (2009) Global bathymetry and elevation data at 30 arc seconds resolution: SRTM30_PLUS. Mar Geod 32:37-41. https:// doi.org/10.1080/01490410903297766

Blanc J, Hall JW, Roche N, Dawson RJ, Cesses Y, Burton A, Kilsby CG (2012) Enhanced efficiency of pluvial flood risk estimation in urban areas using spatial-temporal rainfall simulations. J Flood Risk Manag 5:143-152. https://doi.org/10.1111/j.1753318X.2012.01135.x

Bowman KP (2005) Comparison of TRMM precipitation retrievals with rain gauge data from ocean buoys. J Clim 18(1):178-190. https://doi.org/10.1175/JCLI3259.1

Chabala LM, Kuntashula E, Kaluba P (2013) Characterization of temporal changes in rainfall, temperature, flooding hazard and dry spells over Zambia. Univ J Agric Res 1:134-144. https:// doi.org/10.13189/ujar.2013.010403

Chai T, Draxler RR (2014) Root mean square error (RMSE) or mean absolute error (MAE)? — arguments against avoiding RMSE in the literature. Geosci Model Dev 7:1247-1250. https://doi. org/10.5194/gmd-7-1247-2014

Challinor AJ, Wheeler TR, Craufurd PQ, Slingo JM, Grimes DIF (2004) Design and optimisation of a large-area process-based model for annual crops. Agric For Meteorol 124:99-120

Chanda K, Maity R (2015) Meteorological drought quantification with standardized precipitation anomaly index for the regions with strongly seasonal and periodic precipitation. J Hydrol Eng 12:1-8. https://doi.org/10.1061/(asce)he.1943-5584.0001236

Chen AS, Djordjević S, Leandro J, Savić DA (2010) An analysis of the combined consequences of pluvial and fluvial flooding. Water Sci Technol 62:1491-1498. https://doi.org/10.2166/wst.2010.486

Clark DB (2011) Model Development the Joint UK Land Environment Simulator (JULES), model description - part 2: carbon fluxes and vegetation dynamics. Geosci Model Dev 4:701-722

Creutin JD, Obled C (1982) Objective analyses and mapping techniques for rainfall fields: an objective comparison. Water Resour Res 18:413-431

CSO (2010) 2010 Census of population and housing. Lusaka, Zambia. Retrieved from https://www.zamstats.gov.zm/phocadownload/ ZambiaCensusProjection2011-2035.pdf. Accessed 8 Aug 2018

Derin Y, Yilmaz KK, Derin Y, Yilmaz KK (2014) Evaluation of multiple satellite-based precipitation products over complex topography. J Hydrometeorol 15:1498-1516. https://doi.org/10.1175/ jhm-d-13-0191.1

Duan ZW, Bastiaanssen WGM, Junzhi L (2012). Monthly and annual validation of TRMM mulitisatellite precipitation analysis (TMPA) products in the caspian sea region for the period 1999-2003. In: IEEE International Geoscience and Remote Sensing Symposium, Munich, 2012, pp. 3696-3699. https://doi.org/10.1109/IGARS S.2012.6350613

Funk C, Peterson P, Landsfeld M, Pedreros D, Verdin J, Shukla S, Husak G, Rowland J, Harrison L, Hoell A, Michaelsen J (2015) The climate hazards infrared precipitation with stations-a new environmental record for monitoring extremes. Sci Data. https ://doi.org/10.1038/sdata.2015.66

Goovaerts P (2000) Geostatistical approaches for incorporating elevation into the spatial interpolation of rainfall. J Hydrol 228:113-129

Haberyan KA (2018) A \%3e22,000 years diatom record from the plateau of Zambia. Quaty Res (US) 89:33-42. https://doi. org/10.1017/qua.2017.31

Hachigonta S, Reason CJC (2006) Interannual variability in dry and wet spell characteristics over Zambia. Clim Res 32:49-62. https ://doi.org/10.3354/cr032049 
Hachigonta S, Reason CJC, Tadross M (2008) An analysis of onset date and rainy season duration over Zambia. Theoret Appl Climatol 91:229-243. https://doi.org/10.1007/s00704-007-0306-4

He Z, Yang L, Tian F, Ni G, Hou A, Lu H (2017) Intercomparisons of rainfall estimates from TRMM and GPM multisatellite products over the Upper Mekong River Basin. J Hydrometeorol 18:413430. https://doi.org/10.1175/JHM-D-16-0198.1

Huygen J (1989) Estimation of rainfall in Zambia using meteosat-tir data. Report 12, Wageningen. Retrieved from https://core.ac.uk/ download/pdf/29358705.pdf. Accessed 8 Aug 2018

Janjai S, Nimnuan P, Nunez M, Buntoung S, Cao J (2015) An assessment of three satellite-based precipitation data sets as applied to the Thailand region. Phys Geogr 36:282-304. https://doi. org/10.1080/02723646.2015.1045286

Kang HM, Yusof F (2012) Homogeneity tests on daily rainfall series in Peninsular Malaysia. Int J Contemp Math Sci 7:9-22

Kar AK, Lohani AK, Goel NK, Roy GP (2015) Rain gauge network design for flood forecasting using multi-criteria decision analysis and clustering techniques in lower Mahanadi river basin, India. J Hydrol Reg Stud 4:313-332. https://doi.org/10.1016/j. ejrh.2015.07.003

Lee G, Juncher D (2015) Modelling the local and global cloud formation on HD. Astronomy \& Astrophysics, 1-23. Retrieved from https://arxiv.org/pdf/1505.06576.pdf. Accessed 12 Dec 2018

Libanda B, Ngonga C (2018) Projection of frequency and intensity of extreme precipitation in Zambia: a CMIP5 Study. Clim Res 76:59-72. https://doi.org/10.3354/cr01528

Libanda B, Ngonga C, Zheng M (2019) Spatial and temporal patterns of drought in Zambia. J Arid Land 11:180-191. https://doi. org/10.1007/s40333-019-0053-2

Limao N, Venables AJ (2001) Infrastructure, geographical disadvantage, transport costs, and trade. World Bank Econ Rev 15:451-479

Maggioni V, Vergara HJ, Anagnostou EN, Gourley JJ, Hong Y, Stampoulis D (2013) Investigating the applicability of error correction ensembles of satellite rainfall products in river flow simulations. J Hydrometeorol 14:1194-1211. https://doi.org/10.1175/ JHM-D-12-074.1

Mahmood MI, Elagib NA, Horn F, Saad SAG (2017) Lessons learned from Khartoum flash flood impacts: an integrated assessment. Sci Total Environ 601:1031-1045. https://doi.org/10.1016/j.scito tenv.2017.05.260

Maidment RI, Grimes D, Black E, Tarnavsky E, Young M, Greatrex H, Alcántara EMU (2017) A new, long-term daily satellite-based rainfall dataset for operational monitoring in Africa. Sci Data 4:170063. https://doi.org/10.1038/sdata.2017.63

Majidi M, Alizadeh A, Farid A, Vazifedoust M (2015) Estimating evaporation from lakes and reservoirs under limited data condition in a semi-arid region. Water Resour Manag 29:3711-3733. https://doi.org/10.1007/s11269-015-1025-8

Miceli R, Sotgiu I, Settanni M (2008) Disaster preparedness and perception of flood risk: a study in an alpine valley in Italy. J Environ Psychol 28:164-173. https://doi.org/10.1016/j.jenvp.2007.10.006

Mudenda O, Nkonde E (2018) Lessons from the Modernization of National Meteorological and Hydrological Services. Retrieved from https://www.wmo.int/pages/prog/www/IMOP/documents/ O3_8_Mudenda_ExtendedAbstract.pdf. Accessed 2 Mar 2020

Nasrollahi N (2015) False alarm in satellite precipitation data. In: Improving infrared-based precipitation retrieval algorithms using multi-spectral satellite imagery. Springer Theses (Recognizing Outstanding Ph.D. Research). Springer, Cham

Novella NS, Thiaw WM (2013) African rainfall climatology version 2 for famine early warning systems. J Appl Meteorol Climatol 52:588-606. https://doi.org/10.1175/JAMC-D-11-0238.1

Met Office (2018) Rain and snow-what is precipitation? Retrieved from https://www.metoffice.gov.uk/weather/learn-about/met-offic e-for-schools/other-content/other-resources/what-is-precipitation
Ogwang BA, Guirong T, Haishan C (2012) Diagnosis of SeptemberNovember drought and the associated circulation anomalies over Uganda. Pak J Meteorol 9:11-24

Ogwang BA, Chen H, Li X, Gao C (2014) The influence of topography on east African October-December climate: sensitivity experiments with RegCM4. Adv Meteorol. https://doi. org/10.1155/2014/143917

Oliver MA, Webster R (1990) Kriging: a method of interpolation for geographical information systems. Int J Geogr Inform Syst 4:313332. https://doi.org/10.1080/02693799008941549

Oreggioni WF, Báez BJ (2018) Assessment of satellite-based precipitation estimates over Paraguay. Acta Geophys 66:369-379. https:// doi.org/10.1007/s11600-018-0146-x

Scofield RA, Kuligowski K (2003) Status and outlook of operational satellite precipitation algorithms for extreme-precipitation events. Weather Forecast 18:1037-1051

Shen Y, Xiong A, Wang Y, Xie P (2010) Performance of high-resolution satellite precipitation products over China. J Geophys Res 115(D2):D02114. https://doi.org/10.1029/2009JD012097

Sonkoué D, Monkam D, Fotso-Nguemo TC, Yepdo ZD, Vondou DA (2019) Evaluation and projected changes in daily rainfall characteristics over Central Africa based on a multi-model ensemble mean of CMIP5 simulations. Theoret Appl Climatol 137:21672186. https://doi.org/10.1007/s00704-018-2729-5

Stampoulis D, Anagnostou EN, Nikolopoulos EI (2013) Assessment of high-resolution satellite-based rainfall estimates over the Mediterranean during heavy precipitation events. J Hydrometeorol 14:1500-1514. https://doi.org/10.1175/JHM-D-12-0167.1

Stern RD, Dennett MD, Dale IC (1982) Analysing daily rainfall measurements to give agronomically useful results. Exp Agric $18: 223-236$

Tabios G, Salas J (1985) A comparative analysis of techniques for spatial interpolation of precipitation. JAWRA J Am Water Resour Assoc 21:365-380

TAHMO (2018) The Trans-African HydroMeteorological Observatory. Retrieved from https://tahmo.org/about-tahmo-2/. Accessed 8 Aug 2018

Tarek MH, Hassan A, Bhattacharjee J, Choudhury SH, Badruzzaman AB (2017) Assessment of TRMM data for precipitation measurement in Bangladesh. Meteorol Appl 24:349-359. https://doi. org/10.1002/met.1633

Thomson MC, Connor SJ, Zebiak SE, Jancloes M, Mihretie A (2011) Africa needs climate data to fight disease. Nature 471:440-442. https://doi.org/10.1038/471440a

Tshimanga RM, Tshitenge JM, Kabuya P, Alsdorf D, Mahe G, Kibukusa G, Lukanda V (2016) A regional perceptive of flood forecasting and disaster management systems for the Congo River Basin. Flood Forecast Glob Perspect. https://doi.org/10.1016/ B978-0-12-801884-2.00002-5

Washington R, Harrison M, Conway D, Black E, Challinor A, Grimes D, Todd M (2006) African climate change: taking the shorter route. Bull Am Meteor Soc 87:1355-1366. https://doi. org/10.1175/BAMS-87-10-1355

Watson J, Challinor A (2013) The relative importance of rainfall, temperature and yield data for a regional-scale crop model. Agric For Meteorol 170:47-57. https://doi.org/10.1016/j.agrfo rmet.2012.08.001

WMO (2010) CIMO survey on national summaries of methods and instruments for solid precipitation measurement at automatic weather stations. Retrieved from https://library.wmo.int/doc_num. php?explnum_id=9443. Accessed 2 Feb 2020

Zambrano-Bigiarini M, Nauditt A, Birkel C, Verbist K, Ribbe L (2017) Temporal and spatial evaluation of satellite-based rainfall estimates across the complex topographical and climatic gradients of Chile. Hydrol Earth Syst Sci 21:1295-1320. https://doi. org/10.5194/hess-21-1295-2017 
Zeng Q, Wang Y, Chen L, Wang Z, Zhu H, Li B (2018) Intercomparison and evaluation of remote sensing precipitation products over China from 2005 to 2013. Remote Sens 10:168. https://doi. org/10.3390/rs 10020168
ZMD (2020) Weather information is key. Retrieved from https://zamwe ather.com/about/. Accessed 2 Mar 2020 